\title{
Expert opinions on knowledge-translation interventions for occupational therapists working with neonates in South Africa: A Delphi study
}

\begin{tabular}{|c|c|}
\hline \multicolumn{2}{|c|}{$\begin{array}{l}\text { Authors: } \\
\text { Samantha J. York }{ }^{1} \\
\text { Gina Rencken }{ }^{2} \\
\text { Michael O. Ogunlana } \\
\text { Ayesha Dawood } \\
\text { Pragashnie Govender }\end{array}$} \\
\hline \multicolumn{2}{|c|}{$\begin{array}{l}\text { Affiliation: } \\
\text { 1Private, Samantha Cam } \\
\text { Occupational Therapy, } \\
\text { Durban, South Africa }\end{array}$} \\
\hline \multicolumn{2}{|c|}{$\begin{array}{l}{ }^{2} \text { Department of Occupational } \\
\text { Therapy, Faculty of Health } \\
\text { Sciences, University of } \\
\text { KwaZulu-Natal, Durban, } \\
\text { South Africa }\end{array}$} \\
\hline \multicolumn{2}{|c|}{$\begin{array}{l}{ }^{3} \text { College of Health Sciences, } \\
\text { University of KwaZulu-Natal, } \\
\text { Durban, South Africa }\end{array}$} \\
\hline \multicolumn{2}{|c|}{$\begin{array}{l}{ }^{4} \text { Department of Physiotherapy, } \\
\text { Federal Medical Centre } \\
\text { Abeokuta, Ogun State, Nigeria }\end{array}$} \\
\hline \multicolumn{2}{|c|}{$\begin{array}{l}{ }^{5} \text { Department of Occupational } \\
\text { Therapy, General Justice } \\
\text { Gizenga Mpanza Regional } \\
\text { Hospital, Durban, South Africa }\end{array}$} \\
\hline \multicolumn{2}{|c|}{$\begin{array}{l}\text { Corresponding author: } \\
\text { Pragashnie Govender, } \\
\text { naidoopg@ukzn.ac.za }\end{array}$} \\
\hline \multicolumn{2}{|c|}{$\begin{array}{l}\text { Received: } 23 \text { June } 2021 \\
\text { Accepted: } 22 \text { Oct. } 2021 \\
\text { Published: } 08 \text { Feb. } 2022\end{array}$} \\
\hline \multicolumn{2}{|c|}{$\begin{array}{l}\text { How to cite this article: } \\
\text { York, S.J., Rencken, G., } \\
\text { Ogunlana, M.O., Dawood, A. } \\
\text { \& Govender, P., 2022, 'Expert } \\
\text { opinions on knowledge- } \\
\text { translation interventions } \\
\text { for occupational therapists } \\
\text { working with neonates in } \\
\text { South Africa: A Delphi study', } \\
\text { Health SA Gesondheid 27(0), } \\
\text { a1724. https://doi.org/ } \\
\text { 10.4102/hsag.v27i0.1724 }\end{array}$} \\
\hline \multirow[b]{2}{*}{ 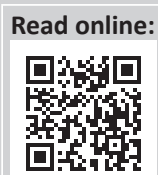 } & \\
\hline & $\begin{array}{l}\text { Scan this QR } \\
\text { code with your } \\
\text { smart phone or } \\
\text { mobile device } \\
\text { to read online. }\end{array}$ \\
\hline
\end{tabular}

\section{Authors:}

Gina Rencken ${ }^{2}$ (I)

Michael O. Ogunlana ${ }^{3,4}$

Ayesha Dawood ${ }^{5}$ (1)

Affiliation:

Occupational Therapy,

Durban, South Africa

Sciences, University of

KwaZulu-Natal, Durban

University of KwaZulu-Natal,

${ }^{4}$ Department of Physiotherapy,

Federal Medical Centre

${ }^{5}$ Department of Occupational

Therapy, General Justice

Gizenga Mpanza Regional

Corresponding author:

Pragashnie Govender,

Dates:

Accepted: 22 Oct. 2021

How to cite this article: York, S.J., Rencken, G., Ogunlana, M.O., Dawood, A. \& Govender, P., 2022, 'Expert translation intervention for occupational therapist working with neonates in South Africa: A Delphi study a1724. https://doi.org/ 10.4102/hsag.v27i0.1724

Read online: to read online.
Background: There is a paucity of literature on knowledge translation (KT) interventions for occupational therapists (OTs) in assessing and caring for the neonate and at-risk infant. Care at this stage of life is paramount, requiring a shift from the survival of the neonate, to the quality of survival. Consequently, clinicians working with neonates have a crucial role in ensuring optimal development and preventing long-term adverse developmental outcomes.

Aim: This study aimed to explore experts' opinions on KT interventions for OTs working with neonates and at-risk infants in South Africa.

Setting: This study was located in South Africa. Due to the virtual nature of data collection, no geographical limitations within the country were imposed.

Method: A two-round Delphi study with a multidisciplinary expert panel $(n=20 ; n=18)$ was conducted. The round one survey was developed based on a literature review, findings from a preceding focus group, and a pilot study. The subsequent round was based on the data and comments generated from the first round. Results were pooled and presented to participants following both rounds.

Results: Consensus on 127 items out of 130 was achieved. These included consensus on the definition of KT in neonatal care, the knowledge that OTs should possess, professional competencies, skills required, professional values, and characteristics. Further agreement was reached on the KT process, the usefulness of KT modalities, recommended courses in neonatal care, barriers to KT, best-practice and requirements for undergraduate training.

Conclusion: Knowledge translation required for OTs working with neonates and at-risk infants were established in this study.

Contribution: This study may be useful for consideration in contextually relevant KT interventions for clinicians working in neonatal care.

Keywords: at-risk infant; childhood development; consensus methodology; Delphi study; early public health sector; knowledge translation; multidisciplinary team; neonatal care; occupational therapy.

\section{Introduction}

The first 28 days of an infant's life, known as the neonatal period, are reported as the most vulnerable as they pose many health risks (World Health Organization 2018). Care at this stage of life is paramount and crucial, requiring a shift from only survival of the neonate to the quality of survival (World Health Organization 2018). Consequently, clinicians working with neonates play an important role in ensuring optimal development and preventing long-term developmental problems (Johnson 2017).

Evidence-based practice and specialised training are essential components that provide occupational therapists (OTs) the foundation to advocate and engage in developmental care in neonatal intensive care units (NICUs) (Legendre et al. 2011). There however, remains limited knowledge on whether occupational therapy (OT) undergraduate programmes adequately prepare OTs for practice in the NICU (Hardy, Govender \& Naidoo 2021).

Johnson (2005) emphasised that being grounded both in knowledge transfer concepts and the knowledge translation (KT) process will lead to more effective exchanges and ultimately

Copyright: (C 2022. The Authors. Licensee: AOSIS. This work is licensed under the Creative Commons Attribution License. 
enhance therapists' translation of evidence into practice. To ensure improved neonatal care, KT must be efficient and optimal. The OTs in South Africa (SA) have been utilising research while practising in the care of neonates and at-risk infants (Lecuona et al. 2016; Perks, Rencken \& Govender 2020); however, there is limited evidence on the application of stakeholder-driven KT interventions for OTs in SA (Govender 2021).

When insufficient information on a topic exists, consensus methodology is often used (Hasson, Keeney \& McKenna 2000). In this article, the authors report on a Delphi study that aimed to gather expert opinions on KT interventions specifically for OTs working with neonates and at-risk infants in the public health sector in SA.

\section{Materials and methods Design}

This study forms part of a more extensive study on KT interventions for neonatal therapists using an appreciative inquiry process and is embedded within the 'design' phase of the process (Figure 1). A two-round Delphi technique, preceded by a rigorous appraisal of the literature, a focus group (Dawood et al. 2022) and a pilot survey, was used (Figure 1). The focus of this study was on the stability of the group consensus. A questionnaire was developed, uploaded onto Google forms, and participants were required to respond using a survey design, with ratings in the form of a Likert scale (Likert 1932; Salutini et al. 2020).

\section{Phase one (item generation)}

- Focus group: A preceding study on appreciating and envisioning knowledge needs in OT intervention for neonates in the public health sector of KwaZulu-Natal $(\mathrm{KZN})$, contributed to the item generation of the survey (Dawood et al. 2022). Core themes that were derived and considered in the development of the Round 1 survey included: information on how knowledge was acquired and synthesised, how knowledge was utilised and translated, contextual barriers and adaptation, and what the ideal OT looked like in a neonatal setting.

- Literature review: A comprehensive literature review was also conducted. Google scholar was used to source evidence using key words such as, 'neonatal care', 'NICU' 'occupational therapy', 'knowledge translation'. The search string included the following: ('infant, newborn' [MeSH Terms] OR ['infant' \{All Fields\} AND 'newborn' \{All Fields\}] OR 'newborn infant' [All Fields] OR 'neonatal' [All Fields] OR 'neonate' [All Fields] OR 'neonates' [All Fields] OR 'neonatality' [All Fields] OR 'neonatals' [All

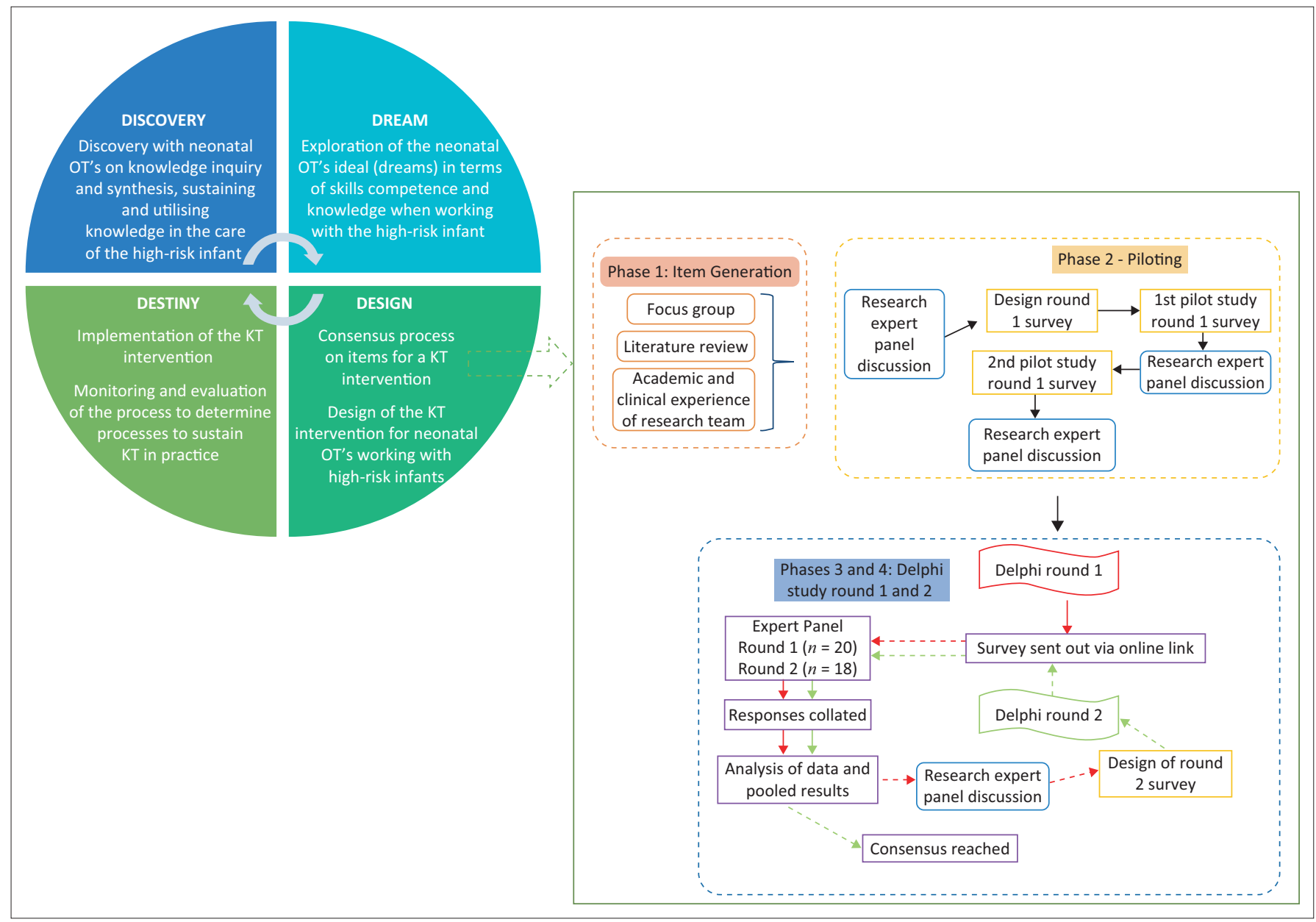

$\mathrm{KT}$, knowledge translation; OT, occupational therapy.

FIGURE 1: Study design (Delphi process) illustrated within the larger study design using appreciative inquiry. 
Fields] OR 'neonates' [All Fields] AND 'care' [All Fields] OR ['intensive care units, neonatal' $\{\mathrm{MeSH}$ Terms\}] OR 'intensive' [All Fields] AND 'care' [All Fields] AND 'units' [All Fields] AND 'neonatal' [All Fields] OR 'neonatal intensive care NICU' [All Fields] OR 'nicu' [All Fields] AND ['occupational therapy' $\{\mathrm{MeSH}$ Terms $\}$ OR 'occupational'] [All Fields] AND 'therapy' [All Fields] OR 'occupational therapy' [All Fields]) AND ['translational medical research' $\{\mathrm{MeSH}$ Terms $\}$ OR \{'translational; (All Fields) AND; medical; \{All Fields\} AND 'research' \{All Fields\}] OR translational medical research' [All Fields] OR ['knowledge' \{All Fields\} AND 'translation' \{All Fields\}] OR 'knowledge translation' [All Fields]).

- Studies undertaken in developed and developing countries were considered to understand best practices in high- and low-resourced areas. Neonatal care in SA was researched systematically, using keywords 'occupational therapy' and 'knowledge translation' to understand current practice and gaps in the literature.

- Research team discussion: Ensuing the focus group and literature review, items for the survey were roughly generated. This was presented to the research team (comprising of two paediatric academics/clinical educators/researchers [PG \& GR], a post-doctoral research fellow/clinician based in sub-Saharan Africa [MOO], and a public sector clinician [AD] working in the field). The items were analysed, and the team contributed to the relevance, comprehensiveness, clarity, and completeness. The pilot study round one was subsequently formulated.

\section{Phase two (piloting)}

Pilot studies for Delphi surveys help identify ambiguities and improve the feasibility of administration (Powell 2003). For this study, experts were selected via purposive convenience sampling. All panellists had no less than three years' experience in neonatal care and had attended training courses in neonatal care. A total of $n=10$ pilot participants commented on the ease of use, the comprehensibility, and the time it took to complete the survey. Participants scored the relevance of each question (using $1=$ not relevant, 2 = somewhat relevant, 3 = quite relevant, $4=$ highly relevant) as recommended by Polit and Beck (2006). The pilot study feedback was conveyed to the research team, interrogated, and relevant changes were effected. To ensure adequate psychometric properties, a second pilot study was undertaken. Five of the 10 pilot participants scored each item's content validity index (Cabatan et al. 2020). This determined which items remained and which were said to be 'irrelevant' and were therefore removed from the questionnaire. This was discussed amongst the research team, and relevant changes were made.

\section{Phase three (round one Delphi process)}

Selection and recruitment of participants: Maximum variation purposive sampling and snowball sampling was used to recruit participants from clinical disciplines of paediatrics, nursing, OT, physical therapy (PT), speech and language therapy (SLT). Distinguishing experts is complex and ambiguous (Du Plessis \& Human 2007; Hasson et al. 2000). Participants who had experience in the field of neonatal care for 2 years or more (Unsworth 2001), were registered with the relevant regulatory body (Health Professions Council of South Africa [HPCSA] or South African Nursing Council [SANC]), and/or had post-graduate training in neonatal care (Bruce, Langley \& Tjale 2008), were recruited. As this study used a homogenous sample (all clinicians working in neonatal care), the sample size, although small, was considered and still yielded sufficient results (Skulmoski, Hartman \& Krahn 2007). A list of 47 potential experts was formulated, and email invitations were sent out inviting participation. Each individual received a consent form, an information sheet and a link to the round one survey. Expertise was documented in a demographic section of the survey.

Round one survey: Each item in the questionnaire required panellists to rate their level of agreement between 1 (strongly disagree) and 10 (strongly agree) on items (Chyung et al. 2017). The items are demonstrated in each of the tables that appear in the results section of this article. Panellists were sent a reminder after 1 and 2 weeks. An a priori threshold of $\geq 70 \%$ for consensus was determined before data collection (Graham, Regehr \& Wright 2003; Naidoo \& Joubert 2013; Perks et al. 2020).

\section{Data analysis}

\section{Rankings}

Descriptive statistics were used to analyse the data using Statistical Package for the Social Sciences (SPSS) version 21 (IBM SPSS Statistics for Windows 2020). The extent to which each participant agreed with the stated issue and the level of agreement between each other (descriptive statistics) (Naidoo \& Joubert 2013) was ascertained. Cronbach's alpha was also used to determine the internal consistency of the group response. Participants' degree of agreement/disagreement was rated on a 10-point scale, where $1=$ strongly disagree, and $10=$ strongly agree. Data were summarised so that each response between 1 and 5 was given a value of 1 to indicate disagreement and each answer between 6 and 10, was given a value of 2 to indicate agreement. Percentages of agreement and disagreement were calculated.

\section{Qualitative comments}

The responses from Round one were analysed using content analysis and assisted in (1) additions and application to the Round two questionnaire and/or (2) comment for general consideration. Similar items were grouped and reported. The content analysis and the statistical summaries contributed to the development of the Round two survey.

\section{Phase four (round two Delphi process)}

Analysis and feedback from participants prior to Round two included a summary table with the percentages of agreement on each item. Items that had reached a consensus 
in Round one were excluded in Round two. The items that did not achieve consensus were included in Round two to allow participants to re-vote. Consensus was reached at this round.

\section{Ethical considerations}

The UKZN Biomedical Research Ethics Committee (approval number: BREC/00001886/2020) approved the study. Ethical principles adhered to in the study included informed consent and autonomy, confidentiality (responses were collated anonymously using an identifying number known only to the authors) and voluntary participation (participants could withdraw from the study with no consequences).

\section{Results}

\section{Demographic profile of panellists}

The multidisciplinary sample comprised $n=20$ participants in Round one and $n=18$ in Round two. Panellists hailed from six out of nine provinces in SA. Experience ranged from 2 to 28 years. Of the 20 panellists, 17 had completed post-graduate courses in paediatric-related fields. Three participants who had not completed post-graduate courses were included in the study, based on having worked clinically for a minimum of 2-3 years in the field (Unsworth 2001). Two panellists functioned within an academic setting (Table 1).

Similar to other SA studies using the Delphi technique to achieve consensus on clinical practice issues, this study used a two-round Delphi (Naidoo \& Joubert 2013; Perks et al. 2020). This was because of the consensus being reached after Round one on all but three sets of items.

\section{Delphi rounds and results}

The Delphi Round one survey comprised 123 items. Seven items were added to the questionnaire for Round two, based on comments made by experts in Round one. Of a total of 130 final items in Round two, consensus was reached for 127 items. The three items not reaching consensus did not warrant an additional Delphi round. The findings are presented against each section with a percentage of agreement achieved in each round.

TABLE 1: Demographic profile of panellists $(n=20)$.

\begin{tabular}{|c|c|c|c|c|c|c|}
\hline Participant & Professional group & Age band & Gender & $\begin{array}{l}\text { Neonatal care } \\
\text { experience } \\
\text { (in years) }\end{array}$ & $\begin{array}{l}\text { Highest level of } \\
\text { education }\end{array}$ & $\begin{array}{c}\text { Geographic } \\
\text { location } \\
\text { (province in S }\end{array}$ \\
\hline P1 & SLT & $31-40$ & $\mathrm{~F}$ & 12 & Masters & Gauteng \\
\hline P2 & OT & $31-40$ & $\mathrm{~F}$ & 10 & Masters & Gauteng \\
\hline P3 & Midwife & $41-50$ & $\mathrm{~F}$ & 28 & Doctorate & Free State \\
\hline P4 & Professional nurse & $41-50$ & $\mathrm{~F}$ & 26 & Diploma & KZN \\
\hline P5 & OT & $31-40$ & $\mathrm{~F}$ & 7 & Masters & KZN \\
\hline P6 & SLT \& Audiologist & $31-40$ & $\mathrm{~F}$ & 5 & Doctorate & Gauteng \\
\hline P7 & Professional nurse & $41-50$ & $\mathrm{~F}$ & 25 & Doctorate & Gauteng \\
\hline P8 & PT & $21-30$ & $\mathrm{~F}$ & 8 & Masters & Gauteng \\
\hline
\end{tabular}

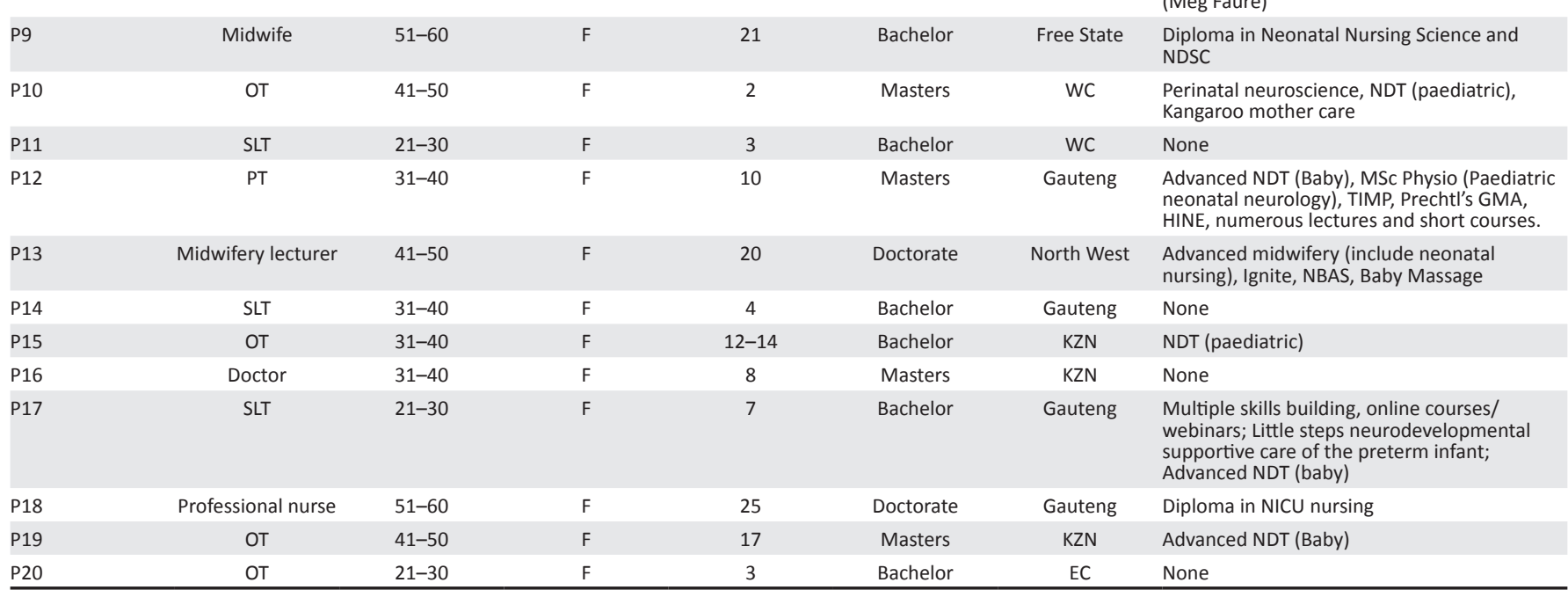

GMA, General Movement Assessment; HINE, Hammersmith Infant Neurological Examination; NANT, National Association of Neonatal Therapists; NBAS, Neonatal Behavioural Scale; NDT, Neurodevelopmental Therapy; NDSC, Neurodevelopmental Supportive Care; SI, Sensory Integration; TIMP, Test of Infant Motor Performance; OT, occupational therapy; SLT, speech and language therapy; PT, physical therapy; KZN, KwaZulu-Natal; WC, Western Cape; EC, Eastern Cape; NICU, neonatal intensive care units; CPR, cardiopulmonary resuscitation; SI, sensory integration; NTNCB, Neonatal Therapy National Certification Board; SA, South Africa. 


\section{Knowledge translation definition}

The Round one survey included nine items related to the definition of KT specifically for OTs working in neonatal care. Consensus was achieved on all items. Experts recommended an additional two items ('KT occurs within a system of interactions among the family' and 'KT aims to optimise enablers'). These items were included in Round two to which the experts agreed with the inclusion (Table 2).

The final definition reads as, the:

$[C]$ omplex and dynamic process which involves attaining, obtaining, synthesising and exchanging evidence, within a system of interactions among the family and multidisciplinary team to optimise enablers, overcome potential barriers to evidence utilisation and adapt to the local context to implement the best possible care for the at-risk infant and family.

\section{Professional knowledge of occupational therapy}

Consensus was reached on all 14 items on the knowledge that OTs should possess on specific diagnoses and interventions. Further exploration of knowledge, for example, understanding 'medical complications', reached consensus on 11 out of 15 items. Four items ('medical treatment protocols', 'effects of medication', 'respiratory support' and 'nutritional support') had an agreement of $\leq 65 \%$ and were included in Round two. The question was also reworded for Round two (from 'has a knowledge on ()...' to 'should have knowledge on ()...') to provide further clarity to experts and therefore all items were included again in round two. Consensus was reached on all 15 items in Round two.

\section{Knowledge translation process and knowledge brokerage}

The necessity of a knowledge broker $(K B)$ and the process of knowledge brokerage achieved 100\% agreement following Round one. Consensus was also reached on all three items related to the KT process in Round one (Table 3).

\section{Knowledge translation modalities}

Concerning the effectiveness of KT modalities, an agreement of $100 \%$ was achieved on all 12 items in round one (Table 4 ).

\section{Courses}

In Round one, not all 20 participants rated every item, the responses varied from 16 to 18 . Three of the listed courses, namely, 'Little Steps Neurodevelopmental supportive care of the preterm infant 4-day course' and '1-day course' and 'Movement Analysis Education Strategies (MAES) Therapy' had an agreement of $\leq 67 \%$. These were included in Round two and an additional five courses as recommended for inclusion by experts. These included 'Special interest webinars or online courses', 'lactation support - Lactation consultant course SA', 'Neuroscience for Improved Neonatal Outcomes (NINO)', Training in administration of 'test of motor infant performance' and 'NDT/Bobath Advanced baby course (post foundation course)'. Of these eight items (three from round

TABLE 3: Knowledge translation process and knowledge brokerage $(n=20)$.

\begin{tabular}{|c|c|c|}
\hline \multicolumn{2}{|c|}{ * Round 1 (\%) } & \multirow[t]{2}{*}{$\mathrm{KT}$ process and knowledge brokerage } \\
\hline Agree & Disagree & \\
\hline 100 & 0 & $\begin{array}{l}\text { KT Process } \\
\text { Building partnerships between researchers, OTs, managers, } \\
\text { and academics within the local context is important in the } \\
\text { knowledge translation process for therapists working with } \\
\text { at-risk infants }\end{array}$ \\
\hline 95 & 5 & $\begin{array}{l}\text { The organisation or managers within the organisation (within } \\
\text { the public sector facility) play an important role in supporting } \\
\text { the process of knowledge translation regarding the care of } \\
\text { the at-risk infant }\end{array}$ \\
\hline 100 & 0 & $\begin{array}{l}\text { National therapy associations should contribute to knowledge } \\
\text { translation through the support of peer-reviewed journals, } \\
\text { position papers, guidelines, conferences and workshops and } \\
\text { through resources and information on the website/page and } \\
\text { in their newsletters }\end{array}$ \\
\hline 100 & 0 & $\begin{array}{l}\text { Knowledge Brokerage } \\
\text { A knowledge broker }(\mathrm{KB}) \text { is necessary in the } \mathrm{KT} \text { process }\end{array}$ \\
\hline 100 & 0 & $\begin{array}{l}\text { A KB should include a 'champion/broker' in the facility that } \\
\text { looks for KT opportunities }\end{array}$ \\
\hline 100 & 0 & $\begin{array}{l}\text { KB should include joint positions between universities and } \\
\text { clinical settings to encourage exchange of information } \\
\text { between clinicians and researchers for the development } \\
\text { and translation of research }\end{array}$ \\
\hline 95 & 5 & KB should include paediatric interest groups for OTs \\
\hline 95 & 5 & KB should include paediatric interest groups for Ots \\
\hline
\end{tabular}

TABLE 2: Definition of knowledge translation for occupational therapy working in neonatal care.

\begin{tabular}{|c|c|c|c|c|}
\hline \multicolumn{2}{|c|}{ Round $1 n=20(\%)$} & \multicolumn{2}{|c|}{ Round $2 n=18(\%)$} & \multirow[t]{2}{*}{ Statements for inclusion in the definition of knowledge translation for OTs working in neonatal care } \\
\hline Agree & Disagree & Agree & Disagree & \\
\hline 95 & 5 & * & * & $\mathrm{KT}$ is a complex and dynamic process \\
\hline 85 & 15 & * & * & KT involves attaining (verb that means reaching or achieving a goal) evidence \\
\hline 95 & 5 & $*$ & * & KT involves obtaining (to take ownership of something and is unrelated to any level of difficulty) evidence; \\
\hline 100 & 0 & $*$ & $*$ & KT involves synthesising (identifying, selecting and combining results from multiple studies) evidence \\
\hline 100 & 0 & * & * & $\begin{array}{l}\text { KT involves exchanging (collaborative problem solving between researchers and decision-makers that happen } \\
\text { through linkage - resulting in mutual learning) evidence }\end{array}$ \\
\hline- & - & 94 & 6 & KT occurs within a system of interactions among the family \\
\hline 100 & 0 & $*$ & * & KT occurs within a system of interactions among a multidisciplinary team \\
\hline- & - & 94 & 6 & KT aims to optimise enablers \\
\hline 100 & 0 & $*$ & $*$ & KT aims to overcome various barriers to evidence utilisation \\
\hline 100 & 0 & $*$ & $*$ & KT strategies should include adaptations to the local context \\
\hline 100 & 0 & * & * & KT aims to apply the best possible care \\
\hline
\end{tabular}

$\mathrm{KT}$, knowledge translation; OT, occupational therapy.

* Consensus reached in Round 1. 
TABLE 4: Knowledge translation modalities for the knowledge translation process $(n=20)$

\begin{tabular}{|c|c|c|}
\hline \multicolumn{2}{|c|}{ * Round $1(\%)$} & \multirow[t]{2}{*}{ KT modalities for the $\mathrm{KT}$ process } \\
\hline Agree & Disagree & \\
\hline 100 & 0 & Making use of multiple sources of evidence \\
\hline 100 & 0 & Clinical experience \\
\hline 100 & 0 & Internet (journal articles, websites) \\
\hline 100 & 0 & Workshops (profession specific) \\
\hline 100 & 0 & Workshops (multidisciplinary team) \\
\hline 100 & 0 & Mentorship \\
\hline 100 & 0 & $\begin{array}{l}\text { Communities of practice (different interest groups, } \\
\text { small-large associations) }\end{array}$ \\
\hline 100 & 0 & $\begin{array}{l}\text { In service training with other members of } \\
\text { multidisciplinary team }\end{array}$ \\
\hline 100 & 0 & In service training and journal reviews \\
\hline 100 & 0 & $\begin{array}{l}\text { Following knowledge acquisitions, consider context and } \\
\text { create protocol }\end{array}$ \\
\hline 100 & 0 & $\begin{array}{l}\text { Following knowledge acquisition, consider context and } \\
\text { update protocol (if there is already protocol in place) }\end{array}$ \\
\hline 100 & 0 & Engage in a reflective process \\
\hline
\end{tabular}

$\mathrm{KT}$, knowledge translation.

* Consensus reached in Round 1.

one and five additional items), consensus was reached on six items. After Round two, a consensus was not achieved for 'MAES therapy' and 'lactation support consultant course SA'.

\section{Barriers to knowledge translation}

Following Round two, only one item, 'lack of financial incentives or promotion opportunities' did not reach a consensus (Table 5).

\section{Best practice for neonatal care}

All items on best practice reached an agreement of $\geq 95 \%$ in Round one and were hence precluded from Round two (Table 6).

\section{Knowledge translation in undergraduate training}

All items on KT for undergraduates reached a $\geq 95 \%$ agreement in Round one and were precluded from Round two.

\section{Reliability and validity}

Conducting research in a team strengthens the research carried out within a Delphi study (Du Plessis \& Human 2007). The additional input from the different researchers in the questionnaire development contributed to verifying the data analysis and promoted the validity of the items generated. The rigorous instrument development process using a literature review, focus groups and research team discussions allowed large amounts of data to be collected and ensured the data was rich and robust (Du Plessis \& Human 2007). The pilot study and panel review also ensured that questions were well-phrased and easy to understand to improve reliability and validity (Hasson et al. 2001). The fact that this study used two successive rounds of the Delphi process also helps in increasing the concurrent validity (Hasson et al. 2000).
TABLE 5: Barriers to knowledge translation.

\begin{tabular}{|c|c|c|c|c|}
\hline \multicolumn{2}{|c|}{ Round $1 n=20(\%)$} & \multicolumn{2}{|c|}{ Round $2 n=18(\%)$} & \multirow{2}{*}{ Barriers to KT } \\
\hline Agree & Disagree & Agree & Disagree & \\
\hline 80 & 20 & $*$ & * & Lack of time to train \\
\hline 80 & 20 & $*$ & * & $\begin{array}{l}\text { Lack of time to integrate knowledge into } \\
\text { practice }\end{array}$ \\
\hline 60 & 40 & 72 & 28 & Lack of available evidence \\
\hline 75 & 25 & $*$ & $*$ & $\begin{array}{l}\text { Lack of confidence in ability to integrate } \\
\text { evidence into practice }\end{array}$ \\
\hline 75 & 25 & * & * & Lack of clinical relevance in training \\
\hline 55 & 45 & 61 & 39 & $\begin{array}{l}\text { Lack of financial incentives or promotion } \\
\text { opportunities }\end{array}$ \\
\hline 90 & 10 & $*$ & * & $\begin{array}{l}\text { The organisation of the healthcare } \\
\text { system (public sector health facilities) }\end{array}$ \\
\hline 75 & 25 & $*$ & $*$ & $\begin{array}{l}\text { Lack of existing recommended standards } \\
\text { of practice }\end{array}$ \\
\hline 95 & 5 & * & * & $\begin{array}{l}\text { Individual healthcare professionals and } \\
\text { their lack of knowledge }\end{array}$ \\
\hline 80 & 20 & $*$ & $*$ & $\begin{array}{l}\text { Attitudes in critically appraising and } \\
\text { using evidence-based practice }\end{array}$ \\
\hline 85 & 15 & * & $*$ & $\begin{array}{l}\text { Skills in critically appraising and using } \\
\text { evidence-based practice }\end{array}$ \\
\hline
\end{tabular}

$\mathrm{KT}$, knowledge translation

* Consensus reached in Round 1.

TABLE 6: Best practice for neonatal care.

\begin{tabular}{|c|c|c|}
\hline \multicolumn{2}{|c|}{ * Round 1 (\%) } & \multirow[t]{2}{*}{ Best practice for neonatal care } \\
\hline Agree & Disagree & \\
\hline 100 & 0 & $\begin{array}{l}\text { Controlling environmental variables (noise, light etc.) to } \\
\text { promote neurodevelopment }\end{array}$ \\
\hline 95 & 5 & $\begin{array}{l}\text { Daily multidisciplinary team interaction to discuss patient } \\
\text { care }\end{array}$ \\
\hline 95 & 5 & Flexible time to care for infants throughout the day \\
\hline 100 & 0 & Time dedicated for family intervention \\
\hline 100 & 0 & Integration of infant into the family unit \\
\hline 100 & 0 & Ensuring a follow up multidisciplinary action plan \\
\hline 100 & 0 & $\begin{array}{l}\text { Monitoring early childhood development for first } 3 \text { years } \\
\text { of life (high-risk baby clinic) }\end{array}$ \\
\hline 100 & 0 & Ensuring infant safety, adaption and development \\
\hline 100 & 0 & $\begin{array}{l}\text { Making use of standardised assessments to monitor } \\
\text { the progress of the infant (e.g. General movements } \\
\text { assessments, Hammersmith Neonatal Neurological } \\
\text { Examination [HNNE]) }\end{array}$ \\
\hline
\end{tabular}

\section{Discussion}

A two-round Delphi process, with a multidisciplinary panel of South African clinicians experienced in the field of neonatal care, were useful in establishing consensus for the definition of $\mathrm{KT}$, professional competencies, the $\mathrm{KT}$ process, the effectiveness of KT modalities, barriers that may impede KT, best practice and $\mathrm{KT}$ for undergraduate training.

\section{Knowledge translation}

Knowledge translation is recognised in OT as a driving force to improve healthcare (Metzler \& Metz 2010). Although the Canadian Institutes of Health Research (2019) coined the term ' $\mathrm{KT}$ ' in 2000 and provided a definition specific to their context, there has been no extension of this definition of KT to particular areas within the practice in OT, let alone neonatal and early intervention care, specifically within a low-resourced context. The definition that the panellists agreed to on KT for neonatal care is aligned to the available literature on $\mathrm{KT}$ and considerations in the care of neonates. It is well known that KT is 'complex' 
(Graham et al. 2006). Existing medical and nursing models do not clearly explain how to systematically integrate research findings within a client-centred practice context (Craik \& Rappolt 2003). Therefore, the definition can assist practitioners in understanding $\mathrm{KT}$ within the context of neonatal care in a low-resourced context. This will enable objective and maximum benefit for policy, practice and patients (Bennett \& Jessani 2011), and could aid in creating a KT model specific to neonatal care. Theories, process models, and frameworks should be considered when developing, implementing or evaluating KT interventions (Tricco et al. 2016). Therefore, having a relevant definition could be a starting point in improving the understanding of KT and how to implement and evaluate KT in this field.

\section{Professional competencies}

One of the issues highlighted within $\mathrm{KT}$ is the growing accumulation of evidence and practitioners' ability to keep up to date (Graham et al. 2006). To identify, review, and select knowledge as recommended by Graham et al. (2006), one needs to understand this knowledge. It is therefore essential to understand the professional competencies required to work in the neonatal field. Working in neonatal care is highly specialised and requires trained professionals to use specialised skills, sophisticated medical procedures and technology to treat fragile infants (Barbosa 2013; Dewire et al. 1996; Hardy et al. 2021; Vergara et al. 2006). This is also highlighted in the Neonatal Therapy Core Scope of Practice (National Association of Neonatal Therapists 2014). Although the operational therapist is not treating the specific diagnosis medically, they need to recognise acutely ill or premature infants' complex medical needs and vulnerabilities. Panellists were required to rate common diagnoses in the NICUs in SA, the most common being, prematurity, birth asphyxia and infection (Limpopo Initiative for Newborn Care 2013). Experts unanimously agreed that OTs needed to have this knowledge.

Procedures, protocols, precautions, and support systems are crucial for the occupational therapist to understand when working in the NICU. Adapting or structuring the environment to enhance function is a well-accepted OT approach. The occupational therapist also needs to have a holistic understanding of the infant and the different interventions to collaborate and provide an environment of developmentally supportive care (Vergara et al. 2006).

\section{Knowledge translation process}

The importance of KT has been receiving increased attention in the literature, especially in healthcare (Graham et al. 2006; Metzler \& Metz 2010). Bennett et al. (2016) recognised the inclusion of a 'knowledge champion' or broker as an enabler of KT for OTs, as did experts in this study, despite limited literature on that role within a low-resourced context. Currently, there are no South African studies that use a KB in KT within occupational therapy. This may prove difficult as this may need to be a position on its own and may require funding (Bennett et al. 2016), limits of which already exist in public hospitals in SA (Buchanan 2011). It may also comprise a clinician who is already working in the setting. The practical implication of this may be problematic as clinicians are already dealing with high caseloads and inadequate time to fulfil all duties (Hardy et al. 2021). The feasibility of the inclusion of this role in the public sector will need careful thought. It may require organisational support as well as OTs to move slightly out of familiar contexts.

\section{Knowledge translation modalities}

All items were agreed as applicable by experts. Both tacit knowledge and explicit knowledge were embedded in this section (David, Poissant \& Rochette 2012). Tacit knowledge is knowledge accumulated through experience and is not explicitly expressed. Although tacit knowledge appears simple, a complex interplay of knowledge and skill is apparent (Metzler \& Metz 2010). It is recommended that clinicians be given time/opportunities to share their knowledge with their team or other clinicians. Knowledge translation interventions at public hospitals should encourage communities of practice or organising forums where clinicians can share their experiences and learn from each other (Metzler \& Metz 2010). Communities of practice (different group's interest groups, small-large associations) could be challenging to implement practically because of time constraints and the ability to connect in KT activities with other clinicians (Bennett et al. 2016; Skulmoski et al. 2007).

\section{Courses}

Not all clinicians are exposed to the same courses and are primarily based on their specific profession. For example, the MAES therapy course is open to various clinicians (doctors, speech and language therapists [SLTs], OTs, physical therapists [PTs]). However, most participants are either OTs or PTs (MAES Therapy 2021). This could be because of the focus of the course being on hands-on therapy rather than a medical approach which may most likely be more applicable to a medical doctor. The lactation consultant course also did not receive consensus. Although many OTs are practising in lactation, they have traditionally not considered breastfeeding within the scope of their profession in the public health sector (Visser et al. 2016). The highest consensus reached was on the course 'IGNITE: Core Training and Mentoring Program for Neonatal Therapists'. This is an international course for OTs, PTs and SLTs that runs over 10 months. Although effective, this may be inaccessible to a large population of OTs because of financial reasons and time constraints. This is supported by recent studies (Dawood et al. 2022; Hardy et al. 2021) that found OTs had insufficient training in neonatal care because of post-graduate courses being unaffordable and not receiving funding from their places of work to improve knowledge and skills.

\section{Barriers to knowledge translation}

Knowledge translation is intended to consider the range of influences affecting incorporating knowledge into practice (Metzler \& Metz 2010). Experts agreed on the many barriers to 
KT (Johnson 2005). The highest agreement amongst experts was 'individual healthcare professionals and their lack of knowledge'. This is concerning as throughout literature, the importance of advanced skills and knowledge for the occupational therapist working in the NICU is highlighted (Hunter, Mullen \& Dallas 1994; Hunter, Lee \& Altimer 2015; Vergara et al. 2006).

After round two, a lack of available evidence was also recognised as a barrier. Further studies should explore whether the availability of evidence is the barrier or how to access evidence; appraisal and understanding of evidence also remains the barrier (Grimshaw et al. 2012). Although consensus on lack of incentives or promotion opportunities were not achieved, this has been identified as a barrier in other studies (Metzler \& Metz 2010). These authors discussed organisations playing a role in promoting $\mathrm{KT}$ through financial incentives or subsidised training as OTs reported that lack of finances hindered KT efforts (Metzler \& Metz 2010). In 2007, the HPCSA implemented a continuing professional development programme to improve the quality of care provided to patients. This entails clinicians participating in post-graduate training, courses and workshops to accumulate continuing education units (CEUs) per 12-month period, including ethics, human rights and medical law (HPCSA 2021). However, South African OTs stated that although these are mandatory, they are not always affordable for the therapists (Dawood et al. 2022).

Lack of time is consistently reported by OTs as a barrier, as was evaluating and applying research knowledge (Metzler \& Metz 2010). According to Metzler and Metz (2010), a therapist's knowledge, expressed through clinical judgement and reflection, are essential tools in identifying barriers and supports. Clinicians need to judge how best to identify potential barriers given their understanding of the context and available resources. Clinicians need to consider these obstacles when planning KT interventions. Removing obstacles at the level of the practice environment is often beyond the control of most practitioners; however, practitioners can influence factors affecting $\mathrm{KT}$ at the level of the person (Metzler \& Metz 2010). These could include a lack of confidence and knowledge, and attitudes in critically appraising and using evidence-based practice. An improved understanding of KT, awareness of personal circumstances, and recent research related to these influences are critical to creating more effective KT strategies. If clinicians have a better understanding of $\mathrm{KT}$, they can design $\mathrm{KT}$ strategies that allow adaptation to the local context (Johnson 2005; Metzler \& Metz 2010).

\section{Best practice}

The at-risk neonate is not well-adapted to the stressful environment of the NICU (Vergara et al. 2006), therefore as experts agreed, controlling environmental variables is integral to best practice. Experts also agreed that daily interactions to discuss patient care forms part of best practice. This is the standard that is included in the Norms and Standards for Essential Care (Limpopo Initiative for
Newborn Care 2013), and is in line with literature that highlights the fragility of the neonate and their ability to change presentation daily (Hunter 1996; Vergara et al. 2006). The other agreed best practices are helpful for clinicians in the field, and therefore should be considered for their training with at-risk infants. They can compare their current practice with what experts regard as 'best practice' and identify potential gaps. Efforts can then be focused on implementing 'best practice' and ultimately enhancing therapy in this area.

\section{Undergraduate training}

In their study, Hardy et al. (2021) ascertained that novice OTs felt underprepared for work in the NICU because of limited or no knowledge or skills from an undergraduate training level. Although practical implementation is complex, academic clinicians need to consider these results when considering undergraduate training for OTs. Although the need for advanced knowledge and skills has been cited in the available literature in SA, novice OTs are expected to work in the NICUs post-undergraduate studies. There is, therefore the need for adequate exposure to the NICU and at-risk infants at an undergraduate level. Knowledge translation for OT student practitioners has also been cited as essential (Govender \& Mostert 2019). Understanding KT aids in the uptake of evidence into practice (Johnson 2005). In line with this, experts agreed that undergraduate training includes increased academic knowledge on KT models, increased practical examples of adapting knowledge to suit the local context and increased collaboration of the MDT in the undergraduate period.

\section{Conclusion}

The two-round Delphi process described in this article was useful in establishing consensus on a definition of KT for OTs within the area of neonates and at-risk infants in the public health sector, professional competencies required of OTs, KT process for OTs, the effectiveness of KT modalities, the barriers that may impede KT, best practice for OTs working with neonates and at-risk infants in public health hospitals and practices included in undergraduate training. Considering that consensus on these factors has been ascertained for OTs, future studies could develop interventions based on these principles and aid in the practical implementation of these KT strategies in the NICUs. Moreover, monitoring and evaluation of KT may be implemented over time. The gap between 'best practice' and current practice and how to improve undergraduate training practically, should also be explored.

\section{Acknowledgements Competing interests}

The authors declare that they have no financial or personal relationships that may have inappropriately influenced them in writing this article. 


\section{Authors' contributions}

P.G. conceptualised the study as principal investigator of the larger project from which this study emanated. S.J.Y. was responsible for executing the study, analysis, interpretation and preparation of the draft manuscript. G.R., M.O.O., A.D. and P.G. made conceptual contributions to the study including data analysis and interpretation. All authors read and approved the final version.

\section{Funding information}

The principal investigator (P.G.) of the larger study, from which this study emanates, has received support from the National Research Foundation (NRF) of South Africa via the Research Development Grants for Y-Rated Researchers Funding instrument, Grant Number 120400 (Reference: CSRP190423432325).

\section{Data availability}

All data generated from this study have been synthesised and reported in this article.

\section{Disclaimer}

The views and opinions expressed in this article are those of the authors and do not necessarily reflect the official policy or position of any affiliated agency of the authors.

\section{References}

Barbosa, V.M., 2013, 'Teamwork in the neonatal intensive care unit', Physical and Occupational Therapy in Pediatrics 33(1), 5-26. https://doi.org/10.3109/0194263 8.2012.729556

Bennett, G. \& Jessani, N., 2011, The knowledge translation toolkit: Bridging the knowdo gap: A resource for researchers, Sage, Thousand Oaks, CA.

Bennett, S., Whitehead, M., Eames, S., Fleming, J., Low, S. \& Caldwell, E., 2016 'Building capacity for knowledge translation in occupational therapy: Learning
through participatory action research', BMC Medical Education 16(1), 1-11. through participatory action research', BMC
https://doi.org/10.1186/s12909-016-0771-5

Bruce, J.C., Langley, G.C. \& Tjale, A.A., 2008, 'The use of experts and their judgments in nursing research: An overview', Curationis 31(4), 57-61. https://doi. in nursing research: An overvio
org/10.4102/curationis.v31i4.1061

Buchanan, H., 2011, 'The uptake of evidence-based practice by occupational therapists in South Africa', World Federation of Occupational Therapists Bulletin 64(1), 29-38. https://doi.org/10.1179/otb.2011.64.1.008

Cabatan, M., Grajo, L. \& Sana, E., 2020, 'Development and content validation of the adaptation process in academia questionnaire for occupational therapy educators', ACTA Medica Philippina 54(2), 142-150. https://doi.org/10.47895/amp.v54i2.1537

Canadian Institutes of Health Research, 2019, Knowledge translation, viewed 27 May 2021, from https://cihr-irsc.gc.ca/e/29529.html.

Chyung, S.-Y., Roberts, K., Swanson, I. \& Hankinson, A., 2017, 'Evidence-based survey design: The use of a midpoint on the likert scale', Performance Improvement 56(10), 15-23. https://doi.org/10.1002/pfi.21727

Craik, J. \& Rappolt, S., 2003, 'Theory of reserach utilisation enhancement: A model for occupational therapy', Canadian Journal of Occupational Therapy 70(5), 266-275. https://doi.org/10.1177/000841740307000503

David, I., Poissant, L. \& Rochette, A., 2012, 'Clinicians' expectations of web 2.0 as a mechanism for knowledge transfer of stroke best practices', Journal of Medical Internet Research 14(5), e121. https://doi.org/10.2196/jmir.2016

Dawood, A., Govender, P., Campbell, S., Rencken, G. \& Ogunlana, M., 2022, Integrating knowledge to practice for occupational therapists working with high-risk infants in the KwaZulu-Natal public health sector: A qualitative explorative inquiry, South African Journal of Occupational Therapy (in review).

Dewire, A., White, D., Kanny, E. \& Glass, R., 1996, 'Education and training of occupational therapists for neonatal intensive care units', American Journal of Occupational Therapy 50(7), 486-494. https://doi.org/10.5014/ajot.50.7.486

Du Plessis, E. \& Human, S.P., 2007, 'Reviewing the art of the delphi technique: Highlighting its scientific merit', Health SA Gesondheid 12(4), 13-24. https://doi. org/10.4102/hsag.v12i4.268
Govender, P., 2021, 'Identifying and bridging the knowledge-to-practice gaps in rehabilitation professionals working with at-risk infants in the public health sector of South Africa: a multimethod study protocol', BMJ 11(5), e039242. https://doi. of South Africa: a multimethod study
org/10.1136/bmjopen-2020-039242

Govender, P. \& Mostert, K., 2019, 'Making sense of knowing: Knowledge creation and translation in student occupational therapy practitioners', African Journal of translation in student occupational therapy practitioners', African Journal of
Health Professions Education 28;11(2), 38. https://doi.org/10.7196/ajhpe.2019. v11i2.1123

Graham, B., Regehr, G. \& Wright, J.G., 2003, 'Delphi as a method to establish consensus for diagnostic criteria', Journal of Clinical Epidemiology 56(12), 1150-1156. for diagnostic criteria', Journal of Clinical Epider
https://doi.org/10.1016/S0895-4356(03)00211-7

Graham, I.D., Logan, J., Harrison, M.B., Straus, S.E., Tetroe, J., Caswell, W. et al., 2006 'Lost in knowledge translation: Time for a map?', The Journal of Continuing Education in the Health Professions 26(1), 13-24. https://doi.org/10.1002/chp.47

Grimshaw, J.M., Eccles, M.P., Lavis, J.N., Hill, S.J. \& Squires, J.E., 2012, 'Knowledge translation of research findings', Implementation Science 7(1), 50. https://doi. org/10.1186/1748-5908-7-50

Hardy, M., Govender, P. \& Naidoo, D., 2021, 'Novice occupational therapist's experience of working in neonatal intensive care units in KwaZulu-Natal', South African Journal of Occupational Therapy 51(1), 27-35. https://doi. org/10.17159/2310-3833/2021/vol51n1a5

Hasson, F., Keeney, S. \& McKenna, H., 2000, 'Research guidelines for the Delphi survey technique', Journal of Advanced Nursing 32(4), 1008-1015. https://doi. org/10.1046/j.1365-2648.2000.t01-1-01567.x

Health Professions Council of South Africa (HPCSA), 2021, Professional practice, viewed 27 May 2021, from https://www.hpcsa.co.za/?contentld=0\&menuSubld= 18\&actionName=Core Operations.

Hunter, J., 1996, 'Clinical interpretation of 'education and training of occupational therapistsfor neonatal care intensive units', American Journal of Occupational Therapy 50(7), 495-503. https://doi.org/10.5014/ajot.50.7.495

Hunter, J., Mullen, J. \& Dallas, D.V., 1994, 'Medical considerations and practice guidelines for the neonatal occupational therapist', The American Journal of Occupational Therapy 48(6), 546-560. https://doi.org/10.5014/ajot.48.6.546

Hunter, J., Lee, A. \& Altimer, L., 2015, 'Neonatal intensive care units', in Occupational therapy for children and adolescents, 7th edn., pp. 595-635, Elsevier, St Louis.

IBM SPSS Statistics for Windows (21.0), 2020, IBM Corp, IBM Corporation, Armonk, New York, NY.

Johnson, L.S., 2005, 'From knowledge transfer to knowledge translation: Applying research to practice', in Canadian association of occupational therapists, pp. $11-14$

Johnson, S., 2017, Occupational therapy in neonatal services and early intervention, p. vii, Royal College of Occupational Therapy, London, viewed 27 May 2021 from https://www.rcot.co.uk/file/1607/download?token=-DeuKXyS.

Lecuona, E., Van Jaarsveld, A., Van Heerden, R. \& Raubenheimer, J., 2016, 'The developmental status and prevalence of sensory integration difficulties in premature infants in a tertiary hospital in Bloemfontein, South Africa', South African Journal of Occupational Therapy 46(1), 15-19. https://doi. org/10.17159/23110-3833/2016/v46n1a5

Legendre, V., Burtner, P.A., Martinez, K.L. \& Crowe, T.K., 2011, 'The evolving practice of developmental care in the neonatal unit: A systematic review', Physical and Occupational Therapy in Pediatrics 31(3), 315-338. https://doi.org/10.3109/0194 2638.2011.556697

Likert, R.A., 1932, 'A technique for measurements of attitude', Archives of Psychology $140,44-53$.

Limpopo Initiative for Newborn Care, 2013, Norms and standards for essential neonatal care, viewed 27 May 2021, from http://www.lincare.co.za/wpcontent/uploads/2016/06/Chapter-2-Norms-and-Standards-for-EssentialNewborn-Care.pdf.

MAES Therapy, 2021, The official global register of MAES trained therapists, We'get'digital, viewed 27 May 2021, from https://www.maestherapy.com/ registered-maes-therapists/.

Metzler, M.J. \& Metz, G.A., 2010, 'Analysing the barriers and supports of knowledge translation using the PEO model', Canadian Journal of Occupational Therapy 77(3), 151-158. https://doi.org/10.2182/cjot.2010.77.3.4

Naidoo, P. \& Joubert, R.W.E., 2013, 'Consensus on hypotonia via delphi process', Indian Journal of Pediatrics 80(8), 641-650. https://doi.org/10.1007/s12098013-1018-7

National Association of Neonatal Therapists, 2014, Neonatal therapy core scope of practice, NANT Professional Collaborative, Cincinnati, $\mathrm{OH}$.

Perks, L.M., Rencken, G. \& Govender, P., 2021, 'Therapists' consensus on an infant massage programme for high-risk infants from resource constrained contexts: A Delphi study', South African Journal of Occupational Therapy 50(3), 72-82. https://doi.org/10.17159/2310-3833/2020/vol50no3a9

Polit, D. \& Beck, C., 2006, 'The content validity index: Are you sure you know what's being reported? Critique and recommendations', Research in Nursing and Health 29, 489-497. https://doi.org/10.1002/nur.20147

Powell, C., 2003, 'The Delphi technique: Myths and realities', Journal of Advanced Nursing 41(4), 376-382. https://doi.org/10.1046/j.1365-2648.2003.02537.x

Salutini, E., Brocco, E., Da Ros, R., Monge, L., Uccioli, L. \& Anichini, R., 2020, 'The complexity of diabetic foot management: From common care to best practice. The Italian expert opinion by Delphi survey', International Journal of Lower Extremity Wounds 19(1), 34-43. https://doi.org/10.1177/1534734619890814 
Skulmoski, G., Hartman, F. \& Krahn, J., 2007, 'The delphi method for graduate research', Journal of Information Technology 6, 1-21. https://doi. org/10.28945/199

Tricco, A.C., Ashoor, H.M., Cardoso, R., MacDonald, H., Cogo, E., Kastner, M. et al. 2016, 'Sustainability of knowledge translation interventions in healthcare decision-making: A scoping review', Implementation Science 11(1), 1-10. https:// doi.org/10.1186/s13012-016-0421-7

Unsworth, C.A., 2001, 'The clinical reasoning of novice and expert occupational therapists', Scandinavian Journal of Occupational Therapy 8(4), 163-173. https:// doi.org/10.1080/110381201317166522
Vergara, E., Anzalone, M., Bigsby, R., Gorga, D., Holloway, E., Hunter, J. et al., 2006, 'Specialised knowledge and skills for occupational therapy practice in the neonatal 'Specialised knowledge and skills for occupationaltherapy practice in the neonatal org/10.5014/ajot.60.6.659

Visser, M., Nel, M., La Cock, T., Labuschagne, N., Lindeque, W., Malan, A. et al., 2016, 'Breastfeeding among mothers in the public health sector: The role of the occupational therapist' South African Journal of Occupational Therapy 46(2), 65-72. https://doi.org/10.17159/2310-3833/2016/v46n2a11

World Health Organization, 2018, Nurturing care for early childhood development, viewed 27 May 2021, from https://www.who.int/publications/i/item/9789241514064. 